\title{
Gynecomastia, CTCAE 5.0
}

National Cancer Institute

\section{Source}

National Cancer Institute. Gynecomastia, CT CAE 5.0. NCI Thesaurus. Code C146685.

A disorder characterized by excessive development of the breasts in males. 